\title{
IMPROVISAÇÃO: descobrir camada por camada
}

\author{
IMPROVISATION: discover layer by layer
}

Zilá Muniz ${ }^{1}$

\section{Resumo}

Este artigo problematiza noções de improvisação em dança como técnica de co-composição emergente de eventos coreográficos. Aponta alguns elementos fundamentais do trabalho de improvisação como: ampliação da consciência do corpo; o atravessamento entre o virtual e atual; distinção entre o voluntário e involuntário, entre o conhecido e o desconhecido; fazer escolhas e tomada de decisões; habilitar restrições e reconhecimento de potencias. Além disso, trata a improvisação com restrições como forma de desenvolver a capacidade de reconhecer as limitações e explorar as possibilidades de movimento dentro destas limitações. Por fim reflete sobre a improvisação como um evento relacional que se constrói a partir das relações que surgem entre todos os elementos que o constituem; é, portanto no "entre" que num campo de forças os elementos se conectam para dar sentido ao evento.

Palavras-chave: Improvisação, Evento Coreográfico, Co-composição.

\section{Resumen}

Este artículo aborda las nociones de improvisación en la danza como una técnica de cocomposición emergente de eventos coreográficos. Señala algunos elementos clave del trabajo de improvisación como: la expansión de la conciencia corporal; el cruce entre lo virtual y real; distinción entre voluntario e involuntario, entre lo conocido y lo desconocido; hacer elecciones y la toma de decisiones; habilitar restricciones lo permiten el reconocimiento de potencial. Por otra parte, la improvisación con restricciones como una forma de desarrollar la capacidad de reconocer las limitaciones y explorar las posibilidades de movimiento dentro de estas limitaciones. Por último refleja en la improvisación como un acontecimiento relacional que se basa en las relaciones que surgen entre todos los elementos que la constituyen; por lo tanto, es el "entre" que un campo de fuerza de los elementos se conectan a darle sentido al evento.

Palabras-clave: Improvisación, Evento Coreográfico, Co-composición.

\begin{abstract}
This study discusses notions of improvisation in dance as an emergent co-composition technique of choreographic events. Points out some key elements of improvisational work as: expansion of body awareness; the crossing between the virtual and actual; distinctions between voluntary and involuntary, between the known and the unknown; choice-making and decision; enabling restrictions and recognition of potentials. Moreover, enabling restrictions in improvisation is a

${ }^{1}$ Doutora em Teatro (2014) pelo Programa de Pós-Graduação em Teatro - UDESC. Diretora e Coreógrafa do Ronda Grupo.
\end{abstract}


way to develop the ability to recognize the limitations and explore the possibilities of movement within these limitations. Finally reflects on improvisation as a relational event that builds on the relationships that arise between all the elements that constitute it; is therefore in the "between" in which the force field connect the elements to make sense of the event.

Keywords: Improvisation, Choreographic Event, Co-composition.

\section{INTRODUÇÃO}

A improvisação é um elemento fundamental para refletir sobre processos de criação e composição na dança assim como possibilita novos modelos de configuração energética para gerar, organizar e perceber o movimento. É uma das práticas corporais que desenvolve a consciência interna dos movimentos e, consequentemente, potencializa a consciência sobre o espaço e tempo. Com a observação de si mesmo a improvisação imprime outra percepção sobre o dançar e, segundo o filósofo José Gil, produz dois efeitos: primeiro, amplia a consciência da escala do movimento; depois, a própria consciência se transforma, deixando de se manifestar como um olhar externo para incorporar-se dele. "A consciência torna-se a consciência do corpo, os seus movimentos enquanto movimento de consciência adquirem as características dos movimentos corporais" (GIL, 2009, p. 109).

Improvisação na dança por si é abrangente e abarca uma série de procedimentos. Essencialmente, é o processo espontâneo para criar movimento e como pesquisa possibilita o desenvolvimento de material, facilitado por meio de uma variedade de explorações criativas. Para Smith-Artaud, autora do livro Dance Composition, "Improvisar é a prática da criatividade ao integrar criação e execução, o bailarino, simultaneamente origina e executa movimentos sem planejamento prévio" (1992, p. 80).

A improvisação como um elemento da cultura afro-americana foi particularmente utilizada na música, principalmente no Jazz, e amplamente explorada por artistas da vanguarda da década de 1960 nos Estados Unidos e na Europa. Como um fenômeno do Jazz, foi trazida e inserida no trabalho de dança pelos artistas pós-modernos americanos. De acordo com Banes, "a tradição afro-americana da improvisação musical foi traduzida para o teatro, para a dança e para outras práticas artísticas da vanguarda branca" (1999, p. 111). Existem muitas tradições improvisatórias de dança e de música enraizadas em culturas não ocidentais, porém não serão tratados neste estudo. 
Ao longo dos últimos cinquenta anos das experimentações da dança pós-moderna, na nova dança, na dança contemporânea, na performance e na dança-teatro, o termo "improvisação" pôde ser aplicado a diferentes modos e procedimentos de trabalho. O que corre especialmente porque as maneiras de apropriação são diversas e com enfoques e abordagens muito particulares. Além disso, a improvisação pode ser utilizada de várias formas: como técnica de construção de um corpo inteligente com atenção no presente; como técnica de criação; como processo de composição em performance; e em composição instantânea, composição no momento ou, ainda, composição em tempo real. Noutros casos, determinado tempo de uma coreografia é reservado para a improvisação dentro de um trabalho quase totalmente fixado e ainda na criação de eventos coreográficos de composição improvisados.

A improvisação, dependendo de como é praticada, é um poderoso recurso para formar bailarinos mais aptos a desenvolver, criar e organizar material coreográfico, o que transformou radicalmente a relação entre intérprete e criador, entre bailarino e coreógrafo. De acordo com Martins (1999), Blom e Chaplin (1982), Smith Artaud (1992), Kaltenbrunner (1998), Banes (2003), Muniz (2004) e Goldman (2010), mais e mais criadores utilizam a improvisação como técnica de composição em processos de colaboração. No processo exploratório entra a participação ativa e criadora dos bailarinos. O que surge do trabalho colaborativo pode ou não ser selecionado e utilizado e as decisões para que tipo de direcionamento é dado para a improvisação e que material é selecionado, habitualmente, vêm do pensamento do coreógrafo, de um processo de criação coletiva ou, ainda, de uma combinação dos dois.

Observa-se que, durante o período de montagem, existe com a improvisação maior possibilidade de criação, pois, proporcionalmente a todos os envolvidos, pensa-se nas conexões e recombinações que podem vir a se potencializar na configuração de uma cadeia associativa mais complexa, abrigando subjetividades diversas. Portanto, a improvisação, seja como pesquisa de vocabulário no processo exploratório, como técnica de composição ou como método de desenvolvimento de jogo, e consequentemente de cenas, aparece como um procedimento sistematizado de experimentação, de seleção e de escolhas.

Além disso, tem a finalidade de criar situações onde surgem novas associações de movimentos, explorando um vocabulário diferenciado ou fazendo surgir novas conexões para um vocabulário já existente. Durante a improvisação, o bailarino executa movimentos em sequências de seu repertório corrente de habilidades. Uma pré-disponibilidade em algum momento faz com 
que uma quebra dessas cadeias habituais aconteça, o que permite que novas cadeias relacionais associativas surjam.

Do mesmo modo, afirma Banes, "O acaso subverte hábitos e permite novas combinações" (1980, p. 16). A improvisação, nesse sentido, cria possibilidades para a descoberta de novos caminhos e formas de resolver problemas dentro de cada evento. A constante atenção exige um estado de alerta que desenvolve e amplia a consciência do corpo, o que torna possível a observação sobre si mesmo. "É alongar a própria consciência para observar a experiência de uma fração de segundos de entrar na "gap" - que constitui o que eu penso como o espaço em que mudamos nossas respostas habituais, assim expandindo a possibilidade de estar no mundo" (ALBRIGHT, 2003, p. 259).

Essa "gap" para Albright é um estado existencial, um momento de suspensão de pontos de referência que propicia novas experiências. Acredito que o estado improvisacional exige um corpo alerta, no qual o bailarino conscientemente analisa, seleciona, resgata e reflete sobre o material que está gerando. Esse estado é algo entre o desperto e o atento: o bailarino não está apenas acordado, mas com uma visível inclinação a perceber e agir. A consciência desloca-se do eu para a relação com o grupo; do corpo em relação ao corpo do outro; do movimento em relação ao tempo e ao espaço; do passado em relação ao presente, pré-articulando o futuro; e do fragmento em relação à criação do todo, simultaneamente à antecipação do próximo momento.

Hougée (1999), assim como Foster (2003) e Albright (2003), faz uma analogia, em alguns momentos a improvisação é adentrar num território conhecido e desconhecido, ao se mover entre o familiar e o que nos é estranho, e também é como seguir os altos e baixos de uma onda. É o que permite esgotar um repertório usual de movimentos e sintonizar-se com camadas mais profundas da memória corporal. É quando os movimentos isolados ou sequências novas para aquele corpo surgem. Também faz surgir no corpo um tipo de movimentação em que a lógica da sequencialidade de movimento acontece de formas diferentes da lógica da sequencialidade de movimento do corpo, que reproduz sequências aprendidas e planejadas.

O movimento no corpo que improvisa pode percorrer caminhos não usuais e promove também a articulação diferenciada do próprio movimento. Porém, com a prática da improvisação, essas sequências lógicas não se definem como modo usual de encadeamento, pois a cada improvisação elas são embaralhadas para se tornarem outras. Como é um processo contínuo de desmanchar hábitos, para quem escolhe improvisar com esta abordagem, a 
improvisação tende a desestabilizar constantemente o repertório de quem a pratica e, ao desmanchar hábitos, recriam-se novos padrões de movimentos. Assim, a repetição faz aparecer novos hábitos, que novamente irão ou poderão se desmanchar para ampliar e ou reorganizar o repertório como expansão dos limites da criação.

O processo de recombinação e reorganização de repertório, portanto, é constante e se a consciência influencia no processo de escolha, podemos encontrar na força do hábito o fator que conduz a escolha para o movimento conhecido, para a repetição, ou seja, para a insistência em realizar certo tipo de movimento ou combinações de movimentos. Daí a necessidade de se aprender a realizar estas "desautomatizações”, uma vez que elas não acontecem no corpo apenas por acionamento de uma vontade de que aconteçam. "O domínio da arte de improvisar leva anos para ser conseguido, tal qual o domínio de toda e qualquer habilidade técnica" (MARTINS, 1999, p. 85).

\section{DESCOBERTA E INVENÇÃO}

Improvisar é imaginar e inventar eventos que acontecem no momento deformador, relacional e transindividual ${ }^{2}$. Uma maneira de problematizar como esses eventos se configuram em composições que tomam formas múltiplas e inéditas é justamente pensar no corpo que improvisa e que atravessa o tempo todo entre o atual e o virtual. Atual e Virtual são conceitos explorados por Deleuze na teoria das multiplicidades. Toda multiplicidade implica elementos atuais e elementos virtuais.

Não há objeto puramente atual. Todo atual rodeia-se de uma névoa de imagens virtuais. Essa névoa eleva-se de circuitos coexistentes mais ou menos extensos, sobre os quais se distribuem e correm as imagens virtuais. É assim que uma partícula atual emite e absorve virtuais mais ou menos próximos, de diferentes ordens. Eles são ditos virtuais à medida que sua emissão e absorção, sua criação e destruição acontecem num tempo menor do que o mínimo de tempo contínuo pensável, e à medida que essa brevidade os mantém, consequentemente, sob um princípio de incerteza ou de indeterminação. Todo atual rodeia-se de círculos sempre renovados de virtualidades, cada um deles emitindo outro, e todos rodeando e reagindo sobre o atual (DELEUZE, 1996, p. 49).

O virtual é co-pertencente ao real e tem pouco a ver com o irreal, pois ele é "[...] um modo de ser fecundo e poderoso, que põe em jogo processos de criação, abre futuros, perfura

${ }^{2}$ Relação transindividual é aquela que ocorre entre realidades pré-individuais e coletivas e não entre indivíduos constituídos (SIMONDON, 1964). 
poços de sentido sob a platitude da presença física imediata” (LÉVY, 1996, p. 12). Trata-se, então, de evitar contrapor o real ao virtual. O virtual é um acontecimento na ordem dos incorporais; ele é força produtiva, efetiva, é real na sua dinâmica e dimensão própria.

O evento de improvisação é experiência de um tempo situado sob o signo de seus elementos de curvatura, de declinação, de inflexão, de bifurcação criadora. Quando o aqui e agora, do virtual ao atual, da atualização do atual pelas diversas virtualizações, não indicam mais do que uma ordem de superposições e, por conseguinte, se é levado a considerar, no ponto de uma imagem do pensamento. Portanto, é co-composição.

$\mathrm{O}$ circuito entre o virtual e o atual corresponde à ruptura mais fundamental do tempo, como tempo-potência contrário a um estado-lugar, estável, cronológico, linear. A cristalização do tempo no evento de dança improvisação, no qual, de dentro do evento coreográfico, podemos ter a sensação de controle e de ser controlado simultaneamente pelo tempo e pelo espaço, é a atualização do virtual em tempo impensável. Quando o corpo é devir corporificado, é “consciência do corpo” (GIL, 2009), é “platitude da presença física imediata” (LÉVY, 1996, p.12). O atual que é a resolução de um problema, este sim, virtual. "A atualização é criação, invenção de uma forma a partir de uma configuração dinâmica de forças e de finalidades" (LÉVY, 1996, p. 16). A atualização é a invenção de uma solução exigida por um complexo problemático por uma bifurcação. E o que é improvisar senão se encontrar a todo instante entre o aqui e agora e a virtualização que é dinâmica e não um modo de ser simples. Desta forma a virtualização é uma problematização de certo atual.

Segundo Lévy, a atualização se desloca de certo problema a uma solução. A virtualização passa de uma solução dada a um (outro) problema. "Ela implica a mesma quantidade de irreversibilidade em seus efeitos, de indeterminação em seu processo e de invenção em seu esforço quanto à atualização. A virtualização é um dos principais vetores da criação de realidade" (1996, p. 18). Por um lado, uma entidade carrega e produz suas virtualidades; vamos tomar como exemplo um acontecimento de dança que reorganiza uma problemática anterior, que habilita restrições e é suscetível de receber interpretações variadas. Por outro lado, o virtual constitui a entidade; as virtualidades inerentes a um ser, sua problemática, o nó de tensões, de coerções e de projetos que o animam e as questões que o movem são parte essencial de sua determinação. 
A criação na improvisação nada mais que a atualização de situações que são dadas, é a resolução de problemas, de charadas de quebra-cabeças. É encontrar a coerência entre a restrição e a liberdade, entre criação e eficácia. Encontrar esses lugares do outro e ao mesmo tempo próprios é o desafio. As regras e restrições dadas fazem parte desse desafio, de buscar na experiência a reunião das percepções distintas. Devemos reconhecer que as relações não derivam da experiência; elas são o efeito dos princípios de associação que, na experiência, constituem um sujeito capaz de ultrapassar a experiência, de ultrapassar neste sentido as restrições e as regras e imaginar e inventar.

A criação e execução são percebidas como um fluxo intensivo da consciência em um movimento de subjetivação, cujo agenciamento de material, fora de qualquer transcendência (do sujeito ou do objeto), é de ajuste da imanência em relação ao devir. Como um continuum de intensidades que compõem o fluxo intensivo da corrente de consciência no movimento dançado e remetem à intensidade da ideia na corrente de pensamento, simultaneamente.

A virtualização é o que fluidifica as distinções instituídas e aumenta os graus de liberdade, cava um vazio motor na questão do novo pela noção do virtual. Experimentar trata precisamente de tornar inesgotáveis os 'aqui' e os 'agora' sempre novos.

\section{FAZER ESCOLHAS NA CRIAÇÃO EM MEIO E POR MEIO DA RESTRIÇÃO}

No trabalho com improvisação a restrição é uma poderosa ferramenta que contribui para acionar um estado de "intuição criativa" que provoca no indivíduo o equilíbrio entre a afetividade a racionalidade, entre o pensar e o agir, entre a intuição e o conhecimento, entre o hábito e o risco. Para Susan L. Foster (2003), improvisar é compor extemporaneamente no impulso do momento e lançar o bailarino entre o conhecido e o desconhecido, entre o familiar e o imprevisível. O conhecido é o espaço, um conjunto de regras pré-estabelecidas, um repertório de movimentos selecionado e a gramática de uma técnica aprendida e incorporada. O desconhecido é tudo que é conhecido e mais o que não foi pensado previamente. Tratar de visitar o desconhecido alarga os limites do conhecido, é o que nos força a ser pegos de surpresa. O encontro entre a improvisação e o desconhecido nunca poderia acontecer sem os elementos conhecidos. 
Ann Cooper Albright (2003), em relação ao impulso que nos leva em busca do desconhecido, da aventura de adentrar territórios e camadas não usuais de nosso repertório, acredita que a potência das práticas improvisacionais, hoje, reside menos na possibilidade de ampliação de repertório, mas sim na compreensão sobre a vontade de atravessar para territórios desconfortáveis, para mover-se em face do medo do que é desconhecido. Esta vontade só é possível pela simples "paradoxalidade, no entanto sofisticada habilidade de estar ao mesmo tempo interna e externamente, ambas abertas e intensamente fundamentadas na consciência de uma experiência em andamento, em curso". (ALBRIGHT 2003, p. 260).

Kent De Spain (2003) descreve a improvisação como outra forma de pensamento. Improvisar seria produzir ideias quase impossíveis ou pouco prováveis de serem concebidas na quietude ou no planejamento prévio do movimento. Em outras palavras, improvisar amplia as possibilidades dos processos de criação onde a imaginação é desencadeada por um procedimento físico. As formulações realizadas pelo corpo em ação transgridem para o estado de consciência do corpo do aqui e agora.

Para Ruth Zaporah (2003), quando falamos em mente e corpo como separados, o que se separa de fato é nossa atenção, e a prática da improvisação desenvolve a esta atenção precisamente. Para Aat Hougée (1999), improvisar requer um estado improvisacional no qual o bailarino se predispõe a desconectar-se de padrões familiares de referências, na tentativa de adentrar territórios desconhecidos.

Danielle Goldman conceitua a improvisação como "aceleração, imaginativa negociação expressiva com restrição” (2010, p. 27). Toda improvisação, ela argumenta, tem algum limite que é justo, frouxo, definido ou vago, e improvisadores procuram alargar ou esticar tais limites. Além disso, Goldman argumenta que a improvisação exige preparação, ensaio e treinamento, de modo que o bailarino pode estar pronto para mover-se com uma diversidade de movimentos em uma paisagem que constantemente se transforma, somando-se a uma contínua interação com os outros bailarinos. A prática constante e o rigor é o que desenvolvem a inteligência do corpo, é o que ensina o improvisador a fazer suas escolhas no momento ao fazer decisões em frações de segundo.

Improvisação não é uma maneira de conquistar a liberdade da restrição ou de quebrar todos os limites; é, de fato, desenvolver a capacidade de reconhecer as limitações e explorar as possibilidades de movimento dentro destas limitações. Goldman descreve improvisação como 
um fenômeno "ao vivo e urgente, que lida com o jogo, é inteligente e trabalha interações espontâneas com restrição" (2010, p. 54).

O modelo de Goldman para a improvisação social como práticas de liberdade está aberto para o movimento dinâmico do espetáculo de dança, mas se aplica a muitos tipos de movimentação, tais como o andado, o falado, o atuado, ou o tocado (instrumento). Isso se aplica a qualquer pessoa que se "move" através da sociedade e interage com outras pessoas e instituições. O indivíduo encontra nessas relações distintas restrições históricas de raça, gênero, sexualidade, classe, e habilidade, dentre outras possibilidades.

Se a improvisação é uma prática de liberdade com restrições, então essas restrições podem ser consideradas "espaços apertados" (GOLDMAN, 2010, p. 64), termo emprestado por Goldman do estudioso literário Houston Baker que ela utiliza para denotar o conjunto de técnicas aprendidas de movimento. Esses não são apenas estilos e movimentos de dança específicos, mas também estão incluídas como parte do repertório de cada indivíduo, as corporalidades impressas por normas de comportamento social.

Enfatizo aqui que tais movimentos são aprendidos culturalmente e reproduzidos como condições históricas nas relações sociais de tempo e espaço particulares, como é o caso de certos comportamentos corporais no ambiente da rua que são retidos, assim como se aprende determinado estilo de dança. Essas corporalidades que fazem parte de um contexto sociocultural se constituem como "espaços apertados", que podem funcionar como restrição e oferecem, portanto, a possibilidade da quebra de padrões para o movimento diferente.

Ademais, os bailarinos, ao se dirigirem a um espaço onde irão dançar, não deixam seus corpos fora antes de entrarem. O corpo que improvisa e dança é o corpo que atravessa a rua, é o corpo que corre na praia, é o corpo que mergulha, é o corpo que realiza todas as ações do cotidiano. As normas que ditam padrões próprios de movimento corporal se relacionam com aspectos da identidade de cada indivíduo/bailarino, incluindo raça, sexo, idade e sexualidade. "Mas um improvisador habilidoso vai estar intimamente familiarizado com os modos habituais de movimento, bem como com as mudanças dos movimentos sociais a que dão significado" (GOLDMAN, 2010, p. 10). Justamente este aspecto, interessante a tantos coreógrafos na dança contemporânea, implica que a diversidade é um fator que pode gerar no campo da dança um ambiente rico e complexo. A exploração dos limites de cada corpo e sua corporalidade é um 
desafio que a consciência do artista desenvolve para descobrir como se mover e inventar dentro desses “espaços apertados”, caracterizando a improvisação.

No evento de improvisação um bailarino é confrontado com um número muito grande de opções que se apresentam no momento. O processo de recombinação e reorganização de repertório - a composição - é constante e deve ser consciente. Se a consciência influencia no processo de escolha, podemos encontrar na força do hábito o fator que conduz "a escolha" para o movimento conhecido, para a repetição, ou seja, para a insistência em realizar certo tipo de movimento ou combinações de movimentos.

Para Katie Duck (1997), a improvisação significa escolha. Escolha dá sentido ao tempo, espaço e movimento. Ao escolher, o improvisador cria um novo espaço com novas opções, não necessariamente inéditos, porém novos para aquele evento ou para aquele indivíduo; ao mesmo tempo, deixa para trás um conjunto de opções invisíveis que não foram selecionadas. $\mathrm{Na}$ improvisação tudo pode acontecer, as opções se encontram em todos os lugares do espaço, mas o fato é que apenas uma coisa acontece em um dado momento. Portanto, as escolhas moldam e estruturam a improvisação. Um bailarino deve estar consciente das escolhas que estão disponíveis no tempo e no espaço e se não fizer uma escolha rapidamente, ele é pego em armadilhas.

Torna-se quase imperceptível a sensação de que o tempo não é mais sentido ou registrado, ele é percebido em termos das ações que se desenrolam, dos movimentos que se conectam e do fluxo que resulta disso. A memória é como um esboço de eventos relacionados e unidos pela imaginação, de tal forma que se torna um diagrama de construção de forças. O diagrama explicado no livro Francis Bacon - Lógica da Sensação de Gilles Deleuze (2007) seria uma máquina abstrata, a emergência de outro mundo, a possibilidade do evento, não o evento em si. Por essa ótica, o diagrama como algo a vir-a-ser é prévio a qualquer objeto, coisa ou evento e por isso não o representa, mas se constitui como a sua possibilidade.

Numa análise da improvisação é importante distinguir entre o voluntário e involuntário, entre o conhecido e o desconhecido, o que também diz respeito às escolhas, à habilidade de discernimento e de seleção, ao acaso e a tomada de decisões. É uma questão de decidir para onde ou como me desloco no espaço, em que posição eu direciono minha cabeça e consequentemente o foco de meu olhar, ou em que tempo eu mudo de comando de um movimento ou em que momento eu acelero ou mudo o ritmo de um movimento repetitivo. O controle sobre meu corpo 
é absolutamente central para a tomada de decisão de uma ação física que se origina de uma vontade.

Este é o poder da vontade, por exemplo, ao tomar uma decisão voluntária de mover-se no espaço, ou de não mover-se e de pausar. Vários fatores afetam esta escolha: a configuração espacial, um dado momento, a própria posição do corpo, as forças gravitacionais e de fricção e um conjunto de opções invisíveis na superfície do espaço de atuação. A decisão voluntária é um ato intencional, consciente, deliberativo. A escolha está intimamente relacionada aos atos voluntários intencionais. As escolhas são feitas sob o escrutínio cortical. Um movimento só pode ser totalmente intencional e consciente quando for resultado da vontade, quando estiver registrado como imagem corporal ${ }^{3}$.

O cérebro nos parece um instrumento de análise com relação ao movimento recolhido e um instrumento de seleção com relação ao movimento executado. Mas, num caso como no outro, seu papel limita-se a transmitir e a repartir movimento. E, tanto nos centros superiores do córtex quanto na medula, os elementos nervosos não trabalham com vistas ao conhecimento: apenas esboçam de repente uma pluralidade de ações possíveis, ou organizam uma delas (BERGSON, 1999, p. 27).

O movimento desloca o corpo em suas relações internas e externas. Cada movimento integra impressões e expressões a todo instante. Cada movimento transforma nossa imagem corporal de forma específica. Nessa perspectiva, os movimentos que realizamos, em termos de sensação e forma, traçam o caminho de nossas transformações, desenhando novas imagens do mundo a partir de renovação da imagem corporal que nos conduzirão a outros movimentos e assim por diante.

Mas então o que fazer com todos os movimentos gerados pelo sistema sinestésico, proprioceptivo e sensorial do esquema corporal ${ }^{4}$ ? O movimento não é liderado por uma ideia fixa

\footnotetext{
${ }^{3}$ Segundo Damásio (2000), padrão neural não é o mesmo que imagem mental, uma vez que esta é uma experiência privada, única, pertencente apenas ao sujeito que a vivencia. Imagem não denota exatamente o padrão de atividades neurais que pode ser encontrado em córtices sensoriais ativados. Nosso padrão neural, mesmo entendido por nós mesmos, seria uma perspectiva em terceira pessoa. Como um padrão neural se torna ou forma uma imagem é uma questão que a neurobiologia ainda não resolveu. As imagens são a moeda corrente de nossa mente. São construídas quando mobilizamos objetos ou quando reconstruímos objetos a partir da memória. Nem todas as imagens que o cérebro constrói se tornam conscientes. O cérebro é um sistema criativo. Cada cérebro constrói mapas do ambiente usando seus próprios parâmetros e sua própria estrutura interna, criando assim um modo único para cada pessoa. A produção de imagens nunca cessa enquanto estamos acordados e continua mesmo durante parte de nosso sono, quando sonhamos. O pensamento é esse fluxo de imagens.

${ }^{4} \mathrm{O}$ esquema corporal é a representação das relações espaciais entre as partes do corpo percebidas cinestesicamente e proprioceptivamente, uma interação neuromotora que permite ao indivíduo estar consciente do seu corpo no tempo e espaço. Trata-se de um fator biologicamente determinado e diretamente relacionado com a organização neurológica
} 
ou plana, uma vez que a referência cortical foi substituída pelo conhecimento proprioceptivo do corpo; é o momento precioso, quando o "corpo toma conta" (FORSYTHE, 1999). A propriocepção é a sensibilidade própria dos músculos e ligamentos, distinta da sensibilidade tátil (exteroceptiva) e da sensibilidade visceral (interoceptiva).

\begin{abstract}
Os músculos e ligamentos registram as condições do movimento que a pele internaliza como qualidades: a rigidez do piso que se apoia quando um indivíduo se olha no espelho, dureza que se torna resistência possibilitando a posição e o movimento; a maciez da pele de um gato se torna lubrificante de um movimento das mãos. Propriocepção traduz o esforço e facilita os encontros do corpo com objetos em memória muscular de relacionalidade. Esta é uma memória cumulativa de habilidades, hábitos e postura. A propriocepção afeta duplamente a tradução do sujeito e do objeto no corpo, a uma profundidade média em que o corpo é apenas corpo, não tendo nada da suposta profundidade do eu nem da superficialidade do encontro externo (MASSUMI, 2002, p. 59).
\end{abstract}

Portanto, é preciso perguntar-se: até que ponto uma escolha é totalmente intencional? Quanto de corporal é o processo de tomada de decisão? Bem, como na improvisação, espaço e tempo são preenchidos com escolhas e as opções estão no "ar". Ao improvisar deve-se reconhecer que, assim que se entra no espaço (espaço de improvisação), faço parte de um evento de tempo/espaço. Sou também responsável pela forma como o espaço se organiza e como o tempo é alongado ou contido. Nesse instante, só pode haver uma chance quando se aceita as possibilidades de escolha.

Ao considerar a escolha como um ato totalmente voluntário da vontade, o conjunto de opções faz parte da consciência e qualquer decisão é consciente. Esse primeiro nível de tomada de decisão é fundamental para a improvisação. É crucial estar consciente de que se pode influenciar ou moldar o espaço improvisado. Portanto, assim que o improvisador entra no espaço, ele é co-responsável pelo desenrolar do acontecimento no tempo/espaço e, nesse ponto, o desafio é encontrar o equilíbrio entre a criação do tempo/espaço e de ser conformado pelo tempo/espaço. Isso significa uma mudança contínua e um "redeslocamento" que acontece a cada momento, porque cada um é responsável pelas escolhas que faz, mas, simultaneamente, é também importante que a escolha possa agir sobre si mesmo. Se vários indivíduos fazem parte do evento de improvisação, então as escolhas surgem do coletivo. Assim, há uma

e com o homúnculo cortical (FREITAS, 2004). Le Boulch (1984) classifica o esquema corporal como o reconhecimento imediato do nosso corpo em função da inter-relação das suas partes, com o espaço e com os objetos que o rodeiam, tanto no estado de repouso como de movimento. 
responsabilidade compartilhada na prática da improvisação. Essa é uma instância de cocomposição, na qual a criação do todo resulta do coletivo e o estado de ser também surge das relações que se constroem a partir das escolhas do grupo.

Quanto ao aspecto do coletivo na improvisação, podemos pensar na ideia de que não apenas os traços individuais da memória fazem parte deste processo, mas entra também a concepção de memória coletiva. Memória coletiva se refere aos processos e estruturas de que o material de memória subjetiva pessoal é trocado entre indivíduos e disponibilizados numa base intersubjetiva. Do ponto de vista subjetivo, pode ser um "corpo instrução", pelo qual um indivíduo tem como referência, apreende ou, ainda, participa com o conteúdo da memória de outro(s) indivíduo(s), mesmo sem contato pessoal direto. A memória coletiva para Damásio (1999) é fundamentada na carne, é intersubjetiva e criada pela comunicação entre os organismos, no caso aqui, os bailarinos/improvisadores.

Na improvisação considero que seja o conhecimento geral construído dentro de um grupo de bailarinos durante o processo de conhecer e reconhecer um ao outro na dança considera-se como memória coletiva e é estruturada na experiência que relaciona estes corpos, e antes mesmo, na vida. É um conjunto de acordos, de regras, de opiniões, de crenças, de estratégias de movimento e de imagens de movimento que certamente são construídos em experiências coletivas anteriores. Memória coletiva estrutural compartilhada corporalmente é, portanto, um conhecimento decorrente de experiências coletivas anteriores. Além disso, também se considera que existe ainda outro aspecto da memória coletiva que é temporária e diz respeito a um conhecimento corporal compartilhado e construído durante o evento no presente.

Os sistemas de memória coletiva estrutural e coletiva temporária influenciam um ao outro. Imagine um grupo de bailarinos que têm trabalhado juntos e frequentemente durante um período de um ano ou mais. Ao longo desse processo, o grupo constrói e se mantém consciente de um conjunto de regras, crenças e estratégias de movimento e de criação que se dão por meio das relações que se estabelecem nas muitas formas de improvisar em cada evento coreográfico. Simultaneamente uma memória coletiva que é, portanto temporária vai sendo construída.

Desse modo, o espaço se constitui de inúmeras camadas de traços de memória que pertencem tanto ao coletivo como ao individual. Esses traços de memória geram pontos de referência considerados como gatilhos invisíveis que relacionam o movimento ao tempo e espaço e que assim que são acessados ativam camadas e camadas de sensação e memória. Acredito que 
essas relações são significativas quando evoluem no momento em que os acontecimentos passados se fundem ao presente para criar novos acontecimentos. Com isso, a presença e o estado de atenção que a improvisação exige nos sintonizam para fazer escolhas perante um conjunto potencial de opções de movimento invisíveis para um movimento que se faz visível no presente.

O que torna rico um processo de criação por meio da improvisação é justamente encontrar possibilidades de experimentação e, conscientemente, desenvolver o eu de cada integrante dentro do grupo. Se pensarmos que um coletivo de improvisadores é composto de eus, o trabalho e o desafio se encontram em fortalecer a unidade do coletivo sem perder a vontade de cada eu. Da mesma forma se na potência de suas individualidades ocorre o enfraquecimento do grupo em termos de co-composição.

Desde que o corpo é capaz de tomar decisões corporais, pelo menos em algum nível intencional, ele contém a capacidade de agir ou reagir em um sentido mais intuitivo. Com isso, no evento de improvisação as soluções para os problemas que surgem acontecem rapidamente. Para Steve Paxton isto é um "reflexo", a operação em que o tempo de reação é curto, porque as decisões corporais ocorrem perto dos músculos. O esquema corporal só permite um curto tempo de reação, no qual as decisões são tomadas de forma mais intuitiva. As escolhas totalmente intencionais são substituídas pelas escolhas parcialmente intencionais. Neste último caso, o corpo segue a sua própria física intrínseca, ou seja, o corpo conhece. Tampouco é possível excluir totalmente a decisão consciente. O que normalmente se percebe é um nó no nível da tomada de decisão consciente, bem como sobre o nível de atos corporais intencionais.

$\mathrm{Na}$ improvisação, é possível estar no espaço improvisacional com ideias previamente fixadas do que irá acontecer se essas ideias servirem como "restrições". Porém, se essas ideias forem determinantes para o que vir a acontecer, no sentido de controle, é inviável e até contra a natureza da improvisação. Principalmente porque escolhas, probabilidade e imprevisibilidade constantemente jogam um com o outro. Se uma escolha for feita, você não tem como prever exatamente o possível resultado da sua ação, pois uma escolha é manipulada pelo tempo/evento de uma forma imprevisível. Não se pode pensar em todas as consequências de um movimento, da mesma forma não há como calcular exatamente tudo que irá acontecer em uma improvisação, principalmente porque esse não é o objetivo dessa forma de dança. É justamente na imprevisibilidade que se define um dos desafios de improvisar. Claro que essa não é uma regra e 
não é correto generalizar, tampouco existe apenas uma maneira de pensar e praticar a improvisação. No entanto, cada núcleo criativo que utiliza a improvisação define suas próprias regras. Mesmo assim, um dos aspectos fundamentais da improvisação com restrições é conhecer que, de dentro da estrutura, é impossível o controle sobre o todo, seja como resultado ou como resolução.

A fim de fazer escolhas, a memória entra como elemento indissociável da inteligência do corpo. Memória está intimamente relacionada à percepção e à ação. A memória é uma reencenação da percepção. Esta afirmação é fundamentada por resultados fenomenológicos da investigação que a atividade neural associada com a memória ocorre de acordo com Antonio Damásio (1996) nos mesmos córtices sensoriais iniciais onde os padrões de disparo correspondentes às representações perceptivas ocorreram uma vez. Percepção é fundamentada no corpo e, uma vez que percepção e memória ocorrem nos mesmos córtices iniciais, pode-se afirmar que a memória é um processo corporal. Uma vez que "eu sou o corpo", qualquer pensamento, plano, ideia, imagem ou memória estão situados no meu corpo e são originários do meu corpo. Somos, portanto, um corpo de memória que funciona no espaço da improvisação. Para Bergson, a sensação é protagonista da memória e do corpo que se aciona, que age.

Ora, o passado imediato, enquanto percebido, é, como veremos, sensação, já que toda sensação traduz uma sucessão muito longa de estímulos elementares; e o futuro imediato, enquanto determinando-se, é ação ou movimento. Meu presente portanto é sensação e movimento ao mesmo tempo; e, já que meu presente forma um todo indiviso, esse movimento deve estar ligado a essa sensação, deve prolongá-la em ação. Donde concluo que meu presente consiste num sistema combinado de sensações e movimentos. Meu presente é, por essência, sensório-motor (BERGSON, 1999, p. 160).

O corpo é o centro da ação. O corpo da memória é um sistema sensório-motor, organizado por padrões e hábitos; isso é chamado de memória de procedimento. É uma memória quase instantânea que diz respeito principalmente ao movimento corporificado. A memória processual contém também o potencial de ação, a possibilidade de ações que ainda não se comprometeram. Anteriormente mencionei que escolha molda tempo, mas talvez seja melhor afirmar que em estruturas de tempo uma escolha torna o presente visível. Eventos passados e futuros emergem, são atualizados nesse momento presente. Tempo é contado em termos de ações: é uma sequência linear e não linear de eventos relacionados, unidos por nossa imaginação. 
O improvisador e o observador entendem um movimento atual em termos de o que aconteceu antes e o que vai acontecer a seguir. É uma maneira de dar sentido a um evento.

$\mathrm{Na}$ dança, como citado anteriormente, o movimento realizado deixa traços na memória (no espaço, no corpo do bailarino, no corpo do observador). Esses traços de memória são como pontos de referência: um movimento é removido, uma construção espacial é reconstruída, o tempo é reformulado. A partir do momento em que o evento começa, experimentamos e reexperienciamos. Assim, um quadro de referências é definido, nossos corpos co-compõem cada momento e as referencias são colocadas novamente em uma constelação de espaço-tempo diferente.

Durante uma improvisação, ações e movimentos são executados e para cada uma dessas ações ou movimentos pode haver ressonâncias no todo. Um exemplo: uma bailarina realiza uma sequência de ações repetidamente por um tempo. Movimentos ou pequenas sequências de movimentos e gestos que aparecem e se repetem manipulam o tempo, porque traços daquelas ações iniciais são revividos e materializam-se novamente. O mesmo vale para os padrões de composição que são traços de memória do espaço.

Nesse sentido, a memória está relacionada com a experiência sensório-motora. Um traço de memória é materializado e realizado no corpo e cria sensações corporais (no espaço, no próprio corpo e nos corpos dos outros bailarinos e espectadores). A memória da sensação é a própria sensação em seu estado de devir quando a progressão da memória se materializa. Um traço de memória que se torna real é um processo natural; uma vez memória-imagem, já é, em parte, uma sensação.

\section{UMA DANÇA DE SENSAÇÃO}

A improvisação no evento de criação em fluxo desencadeia séries de sensações por meio

do ritmo. É preciso deixar fazer-se livremente dentro das restrições e compor no gatilho contínuo que a torna sempre atualização. A sensação como devir conduz à dimensão estética do inacabado. O evento de improvisar não é, portanto, um algo acabado, mas sim, um convite à sensação e à experiência, sem outra direção além do movimento da linha inventada, do traçado ritmado, da cor e da textura presentificada. A sensação é estreitamente relacionada com a memória e com a percepção. Improvisar é ativar o tempo toda essa composição de sensação, 
percepção e memória e ação/movimento em um fenômeno relacional. A percepção que temos em relação a um evento é construída a partir de imagens corporais que se relacionam e se modificam em meu corpo. Improvisar é explorar justamente esse universo infinitamente variável da percepção, no qual o movimento se articula através de um labirinto de possibilidades, despertado pela sensação que desencadeia e pela forma que a percepção atua no discernimento consciente, ou reflexo, para selecionar cada possibilidade em cada momento e descobrir as camadas de possibilidades que emergem.

A percepção nunca está dada por terminada, assim como as nossas perspectivas nos remetem a explicar e pensar num mundo que as englobe, as ultrapasse e anuncie-se por formas sensíveis fulgurantes como uma palavra, um arabesco, uma dobra, um movimento, um gesto. Nesse sentido, é preciso que nossa expressão de mundo seja sensação, isto é, que desperte e reinvoque por inteiro o nosso puro poder de expressar, para além das coisas já vistas. Para Massumi (2003), sensação se relaciona com um campo potência. “A sensação é uma canalização de um campo potência em uma ação local, a partir da qual é novamente transdução para uma reconfiguração global do campo potência. A sensação é o modo em que a potência está presente no corpo que percebe" (2003, p. 75). A percepção é um processo de se tornar consciente de alguma coisa, de conhecer, refere-se à capacidade de diferenciar a informação que está no mundo. Esse processo de compreensão e de entender as informações que estão no mundo é mediado pela experiência e requer o uso dos sentidos para processar dados. Interpretar uma sensação é o que conhecemos como percepção, porém não em sentido cronológico, mas como um emaranhado, sem início nem fim. Esse "campo potência" que se apresenta quando improvisamos exige que aconteça o reconhecimento de certos dispositivos para que o evento se desenvolva e assim, dentro das restrições, a articulação da dramaturgia do corpo se realize.

A percepção não representa algo que é fixo ou constante, mas tem elementos que são fixos num sistema de elementos em constante transformação. Há um imediatismo no que percebemos, mas o que percebemos raramente é sem mediação. Nossas experiências e a cultura estabelecida são os "espaços apertados" que influenciam nossos pensamentos, mas, sem eles, não teríamos nenhuma opção na tentativa de entendimento. O que está dado é simultâneo ao que é originado no momento. Aparentemente, a percepção é um amálgama do consciente e do inconsciente que possui um papel ativo e passivo. Massumi (2003, p. 90) afirma que a percepção está estreitamente relacionada com a ação sobre o que é percebido. As propriedades da coisa 
percebida são também propriedades da ação, mais do que da coisa em si. Não que isso signifique que as propriedades são subjetivas para quem percebe; pelo contrário, são sinais de que aquele que percebe e que é percebido está incluído no mundo de cada um. A percepção se situa entre quem percebe e do que é percebido.

A percepção na improvisação é essa ideia de movimento/ação que tem a sensação como dispositivo; o tempo em que essas operações acontecem sobrepõe-se sobre a memória entre passado, presente e futuro e sobre como são percebidas a cada atualização. O que se desencadeia no processo de co-composição é um redemoinho de pré-articulação de ações e movimentos, disponibilizados e escolhidos tanto intuitivamente como pensados. Para Manning, "a overarticulação é o que vem a ser a força de afluência do desdobramento em potencial de um movimento" (2013, p. 39). Ela nos pede para pensar numa espiral como exemplo, uma espiral como tal não pode ser dançada, é mais duração do que forma. Fazer uma espiral na dança é dançar o futuro de um movimento espiralando. É dançar a over-articulação do presente passando. Ela enfatiza o momento em si passando, visto que qualquer momento pode criar novas escolhas, oportunidades e novos desdobramentos para certos hábitos. O tempo é vivido de uma forma não linear, de forma descontínua.

Nesse sentido, o campo potência é analisado como um campo que forma entidades de diferentes topologias e de diversas ordens causais a partir dos indivíduos e do espaço que se origina e da forma que retorna. Para Massumi (2003, p. 34), esse estado germinal não deve ser considerado uma estrutura implícita ou uma forma, mas deve ser entendido como um feixe de potenciais. Para cada momento de atualização no movimento da criatividade existe a possibilidade emergente de surgir uma forma ou uma estrutura, porém esta se dissolve e se desloca em relação ao próximo momento e agrega nesse processo elementos com os quais está em tensão. Neste sentido o artista/bailarino/improvisador cria técnicas que acionam o desencadeamento de formação do evento, ou da situação que provoca as relações entre as relações que se configuram e que se reconfiguram. As camadas estão todas lá e ativar ou não, reconhecer e desenvolver as possibilidades é parte de um processo de improvisação. Habilitar restrições, reconhecer potencias e adentrar no campo de feixes de um evento coreográfico se constrói a partir das relações que surgem entre todos os elementos que o constituem; é, portanto no "entre" que num campo de forças os elementos se conectam para dar sentido. 


\section{Referências}

ALBRIGHT, Ann Cooper. "Dwelling in Possibility". In: ALBRIGHT, Ann Cooper; GERE, David. Taken By Surprise: A Dance Improvisation Reader. Middleton: Wesleyan University Press, 2003, p. 257-266.

BANES, Sally. Terpsichore in sneakers: post-modern dance. Boston: Houghton Mifflin, 1980.

Greenwich Village 1963: Avant-garde, performance e o corpo efervescente. Rio de Janeiro: Rocco, 1999.

. Spontaneous Combustion: Notes on Dance Improvisation from Sixties to the Nineties. In: ALBRIGHT, Ann Cooper; GERE, David. Taken By Surprise: A Dance Improvisation Reader. Middleton: Wesleyan University Press, 2003, p. 77-88.

BERGSON, Henri. Matéria e Memória: Ensaio sobre a relação do corpo com o espírito. São Paulo: Martins Fontes, 1999.

BLOM, L.; CHAPLIN, L. T. The intimate act of choreography. Pittsburgh: University of Pittsburgh Press, 1982.

DAMÁSIO, A. O Erro de Descartes: Emoção, Razão e o Cérebro Humano. São Paulo: Companhia das Letras, 1996.

. Descartes' Error. New York: Quill, 2000.

. O mistério da consciência. São Paulo: Companhia das Letras, 1999.

DELEUZE, Gilles. Francis Bacon: Lógica da Sensação. Rio de Janeiro: Zahar, 2007.

2003.

. Francis Bacon: The Logic of Sensation. Mineapolis: University of Minnesota Press,

. O atual e o virtual. In: Éric Alliez. Deleuze Filosofia Virtual. (trad. Heloísa B.S. Rocha) São Paulo: Ed.34, pp.47-57, 1996.

DUCK, Katie. Entrevista concedida a David Corbet. In: Dialogues about Dance Improvisation and Performance. Paris: Nouvelles de Dance, 1997.

FORSYTHE, William. Technologies of Improvisation: An Analitycal Tool for the Dance of Eyes. ZKM - Institute for Visual Media, 1999.

FOSTER, Susan Leigh. Taken By Surprise: Improvisation in Dance and Mind. In: ALBRIGHT, Ann Cooper; GERE, David. Taken By Surprise: A Dance Improvisation

FREITAS, G. G. O Esquema Corporal, A Imagem Corporal, A Consciência Corporal e A Corporeidade. Ijuí: Unijuí, 2004.

GIL, José. Movimento Total: O Corpo e a Dança. São Paulo: Iluminuras, 2009. 
GOLDMAN, Danielle. I want to be ready: Improvised Dance as a Practice of Freedom. Ann Harbor: The University of Michigan Press, 2010.

HOUGÉE, Aat In AMORT, Andrea. Improvisation. In: Ballett international - Tanz Aktuell. [S. 1.]: [s. n.], 1999.

KALTENBRUNNER, Thomas. Contact improvisation: moving, dancing, interaction. Aachen: Meyer \& Meyer Verlag, 1998.

LE BOULCH, J. Educação Psicomotora: A psicocinética na idade escolar. Porto Alegre: Artes Médicas, 1984.

LÉVY, Pierre. O que é o virtual? São Paulo: Editora 34, 1996.

MANNING, Erin. Always More Than One: Individuation's Dance. USA: Duke University Press, 2013.

MARTINS, Cleide. A improvisação em dança: um processo sistêmico e evolutivo. Dissertação (Mestrado em Comunicação e Semiótica). Pontifícia Universidade Católica de São Paulo, PósGraduação em Comunicação e Semiótica, São Paulo, 1999.

MASSUMI, Brian. Parables for the virtual: Movement, Affect, Sensation. London: Duke University Press, 2003.

MUNIZ, Zilá. Improvisação como processo de composição na dança contemporânea. Dissertação (Mestrado em Teatro). Universidade do Estado de Santa Catarina, Centro de Artes, Programa de Pós-Graduação em Teatro, Florianópolis, 2004.

PAXTON, Steve. Drafting Interior Techniques. In: ALBRIGHT, Ann Cooper; GERE, David. Taken By Surprise: A Dance Improvisation Reader. Middleton: Wesleyan University Press, 2003, p. 175-184.

SIMONDON, Gilbert. L’Individu et sa Genèse Physicobiologique. Paris: PUF, 1964.

SMITH-ARTAUD, Jacqueline M. Dance composition: a practical guide for teachers. London: A\&C Black Publishers, 1992.

SPAIN, Kent. The Cutting edge of Awareness: Reports from the Inside of Improvisation. In: ALBRIGHT, Ann Cooper; GERE, David. Taken By Surprise: A Dance Improvisation Reader. Middleton: Wesleyan University Press, 2003, p. 27- 40.

ZAPORAH, Ruth. Dance: A Body with a Mind of its Own. In: ALBRIGHT, Ann Cooper; GERE, David. Taken By Surprise: A Dance Improvisation Reader. Middleton: Wesleyan University Press, 2003, p. 21-26. 
Recebido em 28/11/2014

Aprovado em 19/12/2014

Publicado em 13/01/2015 